\title{
A QUEDA E ASCENSÃO DE AUGUSTO MATRAGA
}

João Claudio Arendt ${ }^{1}$

Resumo: Este ensaio analisa o conto "A hora e vez de Augusto Matraga", de Guimarães Rosa, sob a perspectiva da trajetória existencial do protagonista. Busca-se o sentido etimológico da palavra Matraga, o qual é relacionado com a conduta e 0 caráter da personagem, no contexto regional de que emerge. 0 estudo apóia-se em dados históricos sobre o coronelismo e o cangaço brasileiro. Palavras-Chave: Augusto Matraga, Guimarães Rosa, Regionalismo, Cançago, Coronelismo.

Resumen: Este ensayo analiza el cuento "La hora y la vez de Augusto Matraga", de Guimarães Rosa, bajo la perspectiva de la trayectoria existencial del protagonista. Se busca el sentido etimológico de la palabra Matraga, que está relacionado con la conducta y el carácter del personaje, en el contexto regional de lo cual emerge. El estudio se apoya en datos históricos sobre el coronelismo y el bandolerismo propio del nordeste de Brasil.

Palabras Clave: Augusto Matraga, Guimarães Rosa, Regionalismo, Bandolerismo, coronelismo.

Augusto M atraga é um protagonista sob o signo da negação: “M atraga não é M atraga, não é nada". No conto, Augusto Esteves, conhecido pela alcunha de Nhô Augusto, tem sua trajetória existencial marcada pela queda, pela derrota: 0 abandono da esposa, dos amigos, dos homens de confiança, a perda da propriedade, a subseqüente fuga para outras terras e a morte (ascensão).

Filho do Coronel Afonsão Esteves, Nhô Augusto reina quase absoluto (augusto) no arraial da Virgem Nossa Senhora das Dores do Córrego do Murici. M itraga, do árabe clássico, matraga, do árabe vulgar: "martelo para produzir ruído". Matraca, "peça de madeira com uma plaqueta ou argola que se agita barulhentamente em torno de um eixo, usado especialmente como instrumento litúrgico em substituição da sineta durante a quinta-feira e sexta-feira da Semana Santa" (HOUAISS, 2001, p. 1869). Taraq, também do árabe: golpear. Augusto, o Grande, e seu império imposto pela força. Matraga: cetro da Dinastia dos Esteves, no quase fim do mundo do sertão mineiro.

Conforme o narrador, são dele, de Nhô Augusto, o peito largo, o modo alteado, o traje negro, os braços em tenso angulando os cotovelos e a fala

1 Doutor em Letras pela PUCRS; professor no Departamento de Letras e no Programa de PósGraduação em Letras e Cultura Regional da Universidade de Caxias do Sul - UCS. Endereço eletrônico: jcarendt@gmail.com.

2

Personagem do conto "A hora e vez de Augusto Matraga", integrante do livro Sagarana (1946), de João Guimarães Rosa. Todas as citações referentes à leitura do texto serão extraídas da edição de 1984, publicada pela Editora Record, do Rio de Janeiro. 
forte no tumulto da multidão: "- Cinqüenta mil-réis!...". Dele é, também, a mão que alarga pescoções sobre o capiauzinho enamorado da Sariema, muIher-à-toa posta para arremate no leilão: "— Toma! Toma! E Toma!...". Três pancadas com a mão (martelo), três golpes (taraq) de Matraga.

Nhô Augusto, desde pequeno sempre "duro, doido e sem detença, como um bicho grande de mato". Quando adulto, em casa e casado, sabemo-lo sempre fechado em si, sem se importar com a filha; da esposa, Dionóra, gostava da boca e das carnes. "- Por que é que o pai não gosta de nós, mãe?" Na rua: sempre com os capangas, mulheres perdidas, jogo do truque, caçadas. "Mais estúrdio, estouvado e sem regra, estava ficando Nhô Augusto". Mas por causa de dívidas, política do lado que perde, falta de crédito e terras no desmando, inicia a sua queda do alto, como martelo sem a bigorna, matraga sem o prego.

Filho único de pai pancrácio - filho do Coronel Afonsão Esteves, um homem de pouca inteligência e muito pugilato, Nhô Augusto conheceu uma meninice à louca e à larga, nas fazendas do Saco-da-Embira, das Pindaíbas e do Morro Azul. Depois de adulto, prestava para matar por vingança de alguma ofensa: "[...] antes de ir à M ombuca, para matar Ovídio e Dionóra, precisava de cair com o Major Consilva e os capangas". Cegado pela traição de Dionóra, primeira matraga de Augusto, Matraga deixará de ser Matraga, para ser nada: consoante o povo, cobra má, que quem vê tem que matar por obrigação.

E bem assim, vemos Nhô Augusto caindo do cavalo e, sob o riso ruim do Major Consilva, sendo transformado em bigorna dos seus próprios bate-paus; a cabeça, os ombros e as coxas como pregos "sojigados" pela força das matragas carrascas: e "Nhô Augusto ficou estendido, de-bruços, com a cara encostada no chão". Da luta em número desigual, o gigante jaz imóvel, caído por extenso, como víbora em quem se implantassem membros inúteis. Um pouco diferente dos mitos bíblicos, pode-se pensar num Golias abatido por um exército de Davis ou num dragão vencido pela cavalaria de São Jorge: "- Frecha, povo! Desmancha!". Mais ainda: semelhante à fábula infantil, o gigante do péde-feijão sucumbe à astúcia de um bando de pequenos joões.

Como num jogo, aquele que é derrotado jamais está isento do escárnio do vencedor e sua legião de simpatizantes. Por isso, de longe, lá da varanda da sua fortaleza, ecoa a matraga jocosa e má do Major Consilva: " - Não tem mais nenhum Nhô Augusto Esteves, das Pindaíbas, minha gente?!...". Em coro, a torcida dos cacundeiros responde: " - Não tem mais não! Tem mais não!..." Eis aqui, enfim, Herodes, futuro senhor das terras de Nhô Augusto, alargando seu império sobre a região (rex-regionis). 
Uma nota elucidativa de caráter histórico: o coronelismo no Brasil remonta, com certa margem de erro, aos tempos do Império, com a criação da Guarda Nacional, logo após a deposição de D. Pedro I (1831). Colocando à venda os postos de tenente, capitão, major, tenente-coronel e coronel, o governo regencial institucionalizava a prática coronelista, atribuindo poder de mando e desmando aos indivíduos economicamente bem situados. Desse modo, tanto no meio rural quanto no urbano, o coronel (embora sem reconhecimento jurídico) imperava com poder de vida e morte sobre os subalternos (CARVALHO, 1997; QUEIROZ, 1975). Familiares, empregados, escravos e agregados deviamIhe obediência, e poucos ousavam questionar a sua autoridade, fato que apenas acontecia quando outro coronel o desafiasse.

No conto em questão, embora filho de um coronel, Nhô Augusto não ostenta mais patente nenhuma, porque o enredo, ao que tudo indica, situa-se temporalmente na Era Vargas, período em que se praticaram medidas de esvaziamento do poder dos coronéis, com a instituição do voto secreto (e feminino) e a nomeação de interventores e intendentes para administrar estados e municípios. Desse modo, com a morte do Coronel Afonsão Esteves, as dívidas e o descuido das suas posses, Nhô Augusto encontra-se em situação de declínio e desvantagem, sendo derrotado por um velho inimigo do seu pai, o Major Consilva. Nesse contexto, até os homens de confiança desafiam sua autoridade, desertam e se submetem ao comando do adversário. A narrativa Roseana, como se vê, não apenas problematiza o conflito psicológico da protagonista, mas também traz à tona uma faceta notável da crise do coronelismo brasileiro.

\section{***}

Quase nu, picado de faca (a cruzeira espicaçada de que nos fala o narrador Blau Nunes, no conto "Negro Bonifácio", de Simões Lopes Neto), quebrado de pancadas, enlameado de sangue com poeira, Nhô Augusto aguarda o ferro quente na polpa glútea direita. Matraga: ferro de marcar o gado com um triângulo inscrito numa circunferência, indicando a propriedade do Major Consilva: "[...] e imprimiram-na, com chiado, chamusco e fumaça [...]". Esteves: antes Augusto, Nhô Augusto, o soberano; agora nada, boi marcado pela matraga em brasa. Augusto no calvário, sob o malho dos soldados de Herodes.

0 filho do Coronel Afonsão (Esteves!) em nova queda: num último arranco, animal pulando no espaço, como sísifa pedra rolando lá embaixo, no barranco. A seguir, homem branco quase vivo, com um toco de vela benta entre os dedos, no esquife do preto que morava na boca do brejo. Dias de convalescença dentro de um "cofo de barro seco, sob um tufo de capim po- 
dre". Augusto, o homem-boi, suas juntas desconectadas, ossos fraturados, chagas expostas ao repasto das moscas igualmente matragas.

A consciência de Nhô Augusto, matraga a lhe martelar a lembrança da mulher e da filha: "Até que pôde chorar, e chorou muito, um choro solto, sem vergonha nenhuma, de menino ao abandono. E, sem saber e sem poder, chamou alto, soluçando: - Mãe... Mãe...". Matraga: purgatório para a expiação dos crimes.

\section{***}

Órfão desde pequeno, Augusto é criado pela avó de acordo com um projeto para o sacerdócio: "Rezar, rezar, o tempo todo, santimônia e ladainha...". A ausência da figura da mãe e a omissão paterna ("pai era como se Nhô Augusto não tivesse") mostram-se, no texto, fatores cruciais para a formação do caráter da personagem, especialmente no tange ao seu conflito com a autoridade e à incapacidade de demonstrar afeto pela esposa e pela filha. Além disso, o menino tem, na referência familiar, um tio criminoso, "de mais de uma morte", foragido no Saco-da-Embira.

Mas é a ruptura da relação com a mãe biológica e o conseqüente sentimento de orfandade que parecem atormentar Nhô Augusto no momento mais crítico da sua existência. Clamar pela mãe e não pela avó, no contexto da narrativa, pode significar uma intenção de reaver o elo perdido da relação materna, bem como um simbólico retorno à segurança uterina. Ainda nessa perspectiva, é significativo o modo hostil com que Nhô Augusto se relaciona com a esposa e a filha ("- Por que é que o pai não gosta de nós, mãe?"), e com as demais mulheres. Além da indiferença para com Aninha, a esposa tem o mesmo tratamento dispensado às "mulheres-à-toa": "Dela, Dionóra, gostava, às vezes; da sua boca, das suas carnes. Só." Trata-se, pois, de um interesse puramente físico, carnal, erótico, não emocional.

\section{$* * *$}

Destronado, subjugado ao abismo, penitenciado pelas feridas e pelo passado de ruindades, Nhô Augusto clama pela absolvição dos seus pecados. "Matraga não é Matraga, não é nada". É Nhô Augusto - o homem - que, diante de si mesmo, inicia a trabalhosa ascensão: conselhos do padre, o terço, as orações e ladainhas aprendidas com a avó na infância. "[...] e só esperava era a salvação da sua alma e a misericórdia de Deus Nosso Senhor". Haveria de ir para o céu, nem que fosse a porrete (matraga).

0 início da via-crucis: para o norte, na derrota dos criminosos fugidos, viajando à noite, como cativos amocambados. Nhô Augusto e o casal de ne- 
gros, nas brenhas, picadas, penhascos, baixadas, sendas pedregosas, até 0 povoado do Tombador. A travessia dos hebreus rumo à Terra Prometida.

Nhô Augusto - o homem - , Santo Augusto: convertido à fé cristã, torna-se o bom samaritano, sem ganância, sem se importar com os acrescentes: "o que vivia era querendo ajudar os outros". Mourejava até a noite, quando havia luar claro; fugia das tentações: viola, mulheres, bebida, cigarros e armas. Aos domingos, fazia parte "com as velhas corocas que rezavam o terço ou os meses dos santos". Matraca, a anulação do homem na ladainha religiosa: "Cantoria de igreja, dando em cabeça fraca, desgoverna qualquer valente..."

M atraga: memória. "Só o que não podia era se lembrar da sua vergonha; mas ali, naquela biboca perdida, fim de mundo [o deserto], cada dia que descia ajudava a esquecer". Recordar é viver; esquecer é morrer. É Tião da Thereza quem traz notícias do passado-presente a Nhô Augusto: Dionóra, feliz com Ovídio; Miminha, mulher-à-toa; Major Consilva, dono das sua terras; Quim Recadeiro, com 20 balas no corpo. "Só te peço é para você fazer de conta que não meu viu [...], porque é a mesma coisa em como seu eu tivesse morrido mesmo... Não tem mais nenhum Nhô Augusto Esteves, das Pindaíbas, Tião..." A confissão derradeira: Matraga não é nada.

Recordar é sofrer: com o arauto de Tião, a tristeza e uma vontade doente de fazer coisas mal-feitas. Beber e cigarrear, não rezar nem trabalhar (matragas): "haveria de recuperar sua força de homem e seu acerto de outro tempo". O passado, matraga; o presente, matraga. O futuro: "[...] e assim tão mole, tão sem homência, será que eu posso mesmo entrar no céu?!..." A salvação futura, a ascensão: matraga.

0 medo: matraga. 0 homem que já foi zápede (o quatro de paus, no jogo do truque), que pôs fama em feira, que enfrentou dez, que brigou com família inteira, que desarmou e deu pancada (taraq), que desceu a mão (martelo) como monstro matador, tinha ordem de agora fazer alguma vantagem: ao menos honrar o Quim ou procurar a coitadinha da filha. "Mas eu tenho medo...". A confissão: M atraga não é nada.

A tentação das coisas mundanas: matraga. Sentindo mais leve o malho divino sobre as costas cai na tentação de voltar a pitar: "Tirou tragadas, soltou muitas fumaças, e sentiu o corpo se desmanchar...". Não era pecado, porque agora até rezava melhor e devia ficar alegre para a hora da libertação.

Seu Joãozinho Bem-Bem, o mais afamado dos homens dos dois sertões do rio: "o arranca-toco, o treme-terra, o come-brasa, o pega-à-unha, o fechatreta, o tira-prosa, o parte-ferro, o rompe-racha, o rompe-e-arrasa". Seu Joãozinho Bem-Bem: matraga impiedosa. E novas tentações de Nhô Augusto: dois goles de cachaça, dois tiros de carabina. Convidado pelo cangaceiro a se inte- 
grar ao grupo, nova tentação: “Não me tenta, que eu não posso, Seu Joãozinho Bem-Bem". Mas, desonrado, pegado a sua penitência (matraga), "ah, que vontade de aceitar e ir também...", sem pensar em coisa nenhuma de salvação de alma, andar no mundo, de cabeça em pé.

\section{$* * *$}

Outra nota de ordem histórica: o cangaço, no Brasil, constitui um fenômeno surgido em função das precárias condições sociais da população sertaneja e está associado ao que alguns autores chamam de "banditismo social" (MELLO, 1985). Desde o final do século XIX até a metade do século XX, indivíduos abandonados pelo poder político e oprimidos economicamente encontravam guarida na prática bandoleira e passavam a fazer justiça com as próprias mãos. De acordo com Mello (1985), havia pelo menos dois tipos diferentes de cangaço: 0 de vindita e o profissional. No primeiro caso, o indivíduo empunhava uma arma para fazer justiça a alguma ofensa e, em seguida, retornava à sua vida normal; no segundo, o bandoleiro assumia a marginalidade como forma de vida, em busca de liberdade e riqueza.

Em função de o sertanejo possuir um código moral bastante rígido, mas, paradoxalmente, aceitar o homicídio como forma lícita de vingança, os salteadores profissionais não admitiam ser rotulados de bandidos. Por causa disso, desenvolveram um escudo ético, com o qual não só justificavam a si mesmos e à sociedade a natureza dos seus atos, como também criavam uma imagem positivamente orientada. Ao mesmo tempo em que enriqueciam à custa dos seus assaltos, aliavam-se, mediante pagamento, a coronéis que precisavam resolver conflitos de propriedade.

No conto em questão, Joãozinho Bem-Bem e seu bando atuam como cangaceiros profissionais, porque, desviando da milícia oficial, encontram-se a caminho "do Sul, para o arraial das Taquaras, na nascença do Manduri, a chamado do seu amigo Nicolau Cardoso, atacado por um mandão fazendeiro, de injustiça". Não há menção a pagamento em dinheiro, mas subentende-se que algum prêmio, muito mais que a amizade, tenha sido empenhado pelo serviço (pode-se aventar, inclusive, o fator da mútua proteção). Concluída essa tarefa, dirigem-se para o Pilão Arcado, a fim de dar apoio ao "amigo Franquilim de Albuquerque", já que a "política se apostemou".

Entretanto, chama a atenção o código ético e moral dos cangaceiros instituído pelo líder Joãozinho Bem-Bem. Primeiro, destaca-se a vingança contra a família do rapaz que matou à traição Juruminho, um dos integrantes do bando: "Mas a família vai pagar tudo, direito! [...] É a regra". Trata-se de impor autoridade e confiança ao grupo, porque do contrário ninguém "havia de querer obedecer a um homem que não vinga gente sua". Fato semelhante ocorre 242

A Cor das Letras - UEFS, n. 8, 2007 
quando Nhô Augusto, consternado pelas súplicas da família flagelada, desafia o amigo cangaceiro e entra em luta mortal com ele. 0 desenrolar do duelo é significativo para a afirmação desse código ético, porque nenhum dos dois, apesar das mútuas advertências, quer abrir mão da sua honra e se abster do confronto: de seu lado, Nhô Augusto, consciente de que era chegada sua hora e vez, age em prol de uma justiça que envolve a defesa dos mais fracos: "E 0 que vocês estão querendo fazer em casa dele é coisa que nem Deus não manda e nem o diabo não faz!". Já Joãozinho Bem-Bem, embora preso a Nhô Augusto por uma simpatia poderosa, precisa manter a palavra empenhada junto ao bando e não retrocede. Assim, a batalha que se segue, em defesa de duas éticas polarizadas, tem como termo a destruição apenas física dos envolvidos.

\section{***}

Um sonho: matraga. Um deus valentão, como Seu Joãozinho Bem-Bem, que mandava Nhô Augusto brigar. Os dias seguem seu curso: 0 hábito da cachaça, para dormir, para não apanhar resfriado. E a saudade de mulheres (matragas); penitências com o diabo ao lado, para dar mais sabor à salvação.

“- Adeus, minha gente, que aqui é que mais não fico, porque a minha vez vai chegar, e eu tenho que estar por ela em todas as partes!". A partida num jumento, animal que conduziu o menino Jesus até Jerusalém. 0 jumento, símbolo da modéstia, traz uma cruz desenhada nas costas. Antes, Augusto Matraga montado num cavalo; agora, Nhô Augusto, cruzando o sertão num asno, em busca da salvação. "Aonde o jegue quiser me levar, nós vamos, porque estamos indo é com Deus!...". Santo Augusto, monge franciscano em comunhão com a natureza.

A chegada ao arraial do Murici: Seu Joãozinho Bem-Bem, o amigo, o compadre, o primo, o mano de Nhô Augusto, descendo a matraga sobre a família de João Lomba, para vingar a morte à traição de um dos seus guerreiros. A revelação suprema de Nhô Augusto diante da injustiça: na luta fratricida (Caim e Abel), ambos tombam mortalmente. Mas morrem como parentes, como irmãos, em tudo iguais e valentes, no mesmo desejo de dar cabo à existência sórdida (existência matraga), quiçá conscientes de que a vida é uma agitação feroz e sem finalidade.

Nhô Augusto não é mais (m)Matraga: a lâmina com que talhou Seu Joãozinho Bem-Bem partiu de baixo, não de cima. Foi do púbis à boca-doestômago, num movimento inverso ao da matraga (martelo): o movimento da ascensão. Nhô Augusto, "o homem mais maneiro de junta e de mais coragem que já conheci!...". Nhô Augusto, o mártir, o santo: "- Traz meus filhos, para agradecerem a ele, para beijarem os pés dele!... Não deixem este santo morrer assim...". Finalmente, a ascensão: libertação. 
Uma rápida nota à guisa de conclusão: Rodrigo Cambará, no primeiro livro da trilogia 0 tempo e o vento, tem um percurso existencial muito parecido com o de Nhô Augusto. Altivo, provocador, bem montado num cavalo, usando um dólmã militar, um chapéu com barbicacho, esporas, um violão a tiracolo e um lenço vermelho no pescoço, Rodrigo Cambará veio "ninguém sabe de onde" para mudar o destino dos habitantes de Santa Fé, povoado imaginário perdido nos confins do pampa gaúcho: "- Buenas e me espalho! Nos pequenos dou de prancha e nos grandes dou de talho!"

Como o frondoso cambará, o Capitão Rodrigo impõe sua majestade por meio do porte físico e de um indescritível fascínio pessoal. Como passatempo, o que mais o atrai é o exercício bélico: seu passado contabilizava diversas escaramuças na Banda Oriental, durante a tentativa de domínio português sobre Montevidéu. Em 1828, instalado em Santa Fé, casado com Bibiana Terra, dirigindo um armazém, mas irremediavelmente perdido na jogatina, na bebedeira e nos casos extraconjugais, Rodrigo aguarda a explosão de nova revolução: "Um dia a guerra vem". Antes disso, porém, com a morte prematura da filha Anita e visivelmente arrependido por Ihe omitir socorro ("'Sua filhinha está muito mal'... Pois que esteja. Mulher não faz falta no mundo. Que morra!"), ele muda seu modo de ser e passa a dedicar-se à família, à casa de negócios, abstendo-se de beber e jogar.

Quando estoura a Revolução Farroupilha, em 1835, Rodrigo Cambará, 0 homem que tinha "medo de viver, não de morrer", e acreditava ainda não ter sido fabricada a bala que pudesse matá-lo, sucumbe com um tiro no peito em meio à batalha. A consternação é geral em Santa Fé, e até Padre Lara não consegue conter as lágrimas pela queda do majestoso (c)Cambará: "- Nunca vi cristão que gostasse mais de brigar que o Cap. Rodrigo".

Rodrigo Cambará (O continente, 1949) e Augusto Matraga (Sagarana, 1946) são personagens cujas existências, desde o nascimento até a morte, parecem se espelhar. Excetuando 0 aspecto da atuação bélica, em função de as narrativas remeterem a dois espaços e tempos históricos diferentes (primeira metade do século XIX, no Rio Grande do Sul, e primeira metade do século XX, em M inas Gerais), Rodrigo Cambará e Augusto M atraga apontam para dois indivíduos que incorporam características míticas. Aquele, protótipo do gaúcho guerreiro; este, exemplo do sertanejo valente. M esmo sensivelmente idealizados, ambos constituem admiráveis sínteses da experiência humana regional com indiscutível validade universal. 


\section{REFERÊNCIAS}

DICIONÁRIO HOUAISS DE ĹNGUA PORTUGUESA. Rio de Janeiro: Objetiva, 2001.

CARVALHO, José Murilo de. Mandonismo, coronelismo, clientelismo: uma discussão conceitual. Dados - Revista de Ciências Sociais, Rio de Janeiro, v. 40, n. 2, p. 229- 250, 1997.

M ELLO, Frederico Pernambucano de. Guerreiros do sol: o banditismo no Nordeste do Brasil. Recife: Massangana, 1985.

QUEIROZ, M aria Isaura Pereira de. O Coronelismo numa interpretação sociológica. In: FAUSTO, Boris. (Org.). História geral da civilização brasileira. São Paulo: DIFEL, 1975, t. III, v. 1, p. 155-190. ROSA, João Guimarães. Sagarana. Rio de Janeiro: Record, 1984.

VERISSIM O, Erico. O continente, v. 1. 28. ed. São Paulo: Globo, 1991. 
